\title{
Lifespan extension and delay of age-related functional decline caused by Rhodiola rosea depends on dietary macronutrient balance
}

\author{
Dmytro V Gospodaryov ${ }^{1}$, Ihor S Yurkevych ${ }^{1}$, Mahtab Jafari ${ }^{2}$, Volodymyr I Lushchak ${ }^{1}$ and Oleh V Lushchak ${ }^{1,3^{*}}$
}

\begin{abstract}
Background: This study was conducted to evaluate the effects of rhizome powder from the herb Rhodiola rosea, a traditional Western Ukraine medicinal adaptogen, on lifespan and age-related physiological functions of the fruit fly Drosophila melanogaster.

Results: Flies fed food supplemented with $5.0 \mathrm{mg} / \mathrm{ml}$ and $10.0 \mathrm{mg} / \mathrm{ml}$ of $R$. rosea rhizome powder had a $14 \%$ to $17 \%$ higher median lifespan, whereas at $30.0 \mathrm{mg} / \mathrm{ml}$ lifespan was decreased by $9 \%$ to $12 \%$. The preparation did not decrease fly fecundity.

The effect of $R$. rosea supplement on lifespan was dependent on diet composition. Lifespan extension by 15\% to $21 \%$ was observed only for diets with protein-to-carbohydrate ratios less than 1 . Lifespan extension was also dependent on total concentration of macronutrients. Thus, for the diet with 15\% yeast and $15 \%$ sucrose there was no lifespan extension, while for the diet with protein-to-carbohydrate ratio 20:1 $R$. rosea decreased lifespan by about $10 \%$.

Flies fed Rhodiola preparation were physically more active, less sensitive to the redox-cycling compound menadione and had a longer time of heat coma onset compared with controls. Positive effects of Rhodiola rhizome on stress resistance and locomotor activity were highest at the 'middle age'.
\end{abstract}

Conclusions: The present data show that long-term food supplementation with $R$. rosea rhizome not only increases $D$. melanogaster lifespan, but also delays age-related decline of physical activity and increases stress resistance, what depends on protein-to-carbohydrate ratio of the diet.

Keywords: Adaptogen, Diet, Fecundity, Fruit fly, Longevity, Macronutrient balance, Rhodiola rosea

\section{Background}

Over the past few decades, the fruit fly Drosophila melanogaster, nematode Caenorhabditis elegans, and budding yeast Saccharomyces cerevisiae have been extensively used for lifespan studies because of their relatively short lifecycles and, especially, the ease of producing knockouts of specific genes. In addition to genetic manipulations, these organisms are also used in the search for anti-aging medicinal preparations. For instance, studies on S. cerevisiae disclosed anti-aging properties of resveratrol, a plant-derived compound, well established by

\footnotetext{
*Correspondence: olehl@pu.if.ua

'Department of Biochemistry and Biotechnology, Vassyl Stefanyk Precarpathian National University, Ivano-Frankivsk 76025 Ukraine

${ }^{3}$ Department of Zoology, Stockholm University, S-10691 Stockholm, Sweden Full list of author information is available at the end of the article
}

its presence in some types of wine. Drosophila has also been checked for anti-aging properties of resveratrol $[1,2]$, as well as 4-phenylbutyrate [3], caffeine [4], curcumin [5], statin [6], Rhodiola rosea [7,8] and Rosa damascena [9], blueberry extract [10] and many other preparations. Changes in diet composition, namely dietary and caloric restriction, were also found to extend fruit fly lifespan [11]. Several molecular mechanisms have been proposed for dietary or drug-mediated longevity enhancement. In particular, FOXO (forkhead box O), TOR (target of rapamycin) and AMPK (AMP-activated protein kinase) signaling pathways are believed to be involved in lifespan-prolonging effects of many treatments, as determined by experiments conducted on fruit fly models $[12,13]$. These pathways are now extensively investigated in many aspects, and many interconnections between

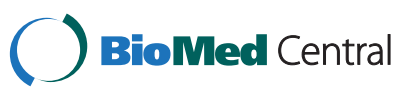


them have already been reported. One of the common features of all these signaling pathways is their relation to the stress resistance of organisms $[12,14]$.

Notably, in many cases, an extended lifespan is accompanied by an increased stress resistance of survivors who have consumed food supplemented with an anti-aging medication. Moreover, one of these life-prolonging preparations, Rhodiola rosea, is a well-known adaptogenic herb. This plant is widely used in folk medicine among Ukrainians living in the Carpathian Mountains, as well as among people in other regions of Eurasia, including Finland, Russia, and China. Preparations from rhizome-like roots of this plant are shown to have cardioprotective, antidepressant, anticancer, antihyperglycemic, antinarcotic, and other beneficial activities $[15,16]$. Multiple studies reported that $R$. rosea extract can enhance resistance to heat stress, heavy metals, and redox-cycling agents [17]. Experiments on the adaptogenic properties of $R$. rosea have been conducted in animal models, including rats $[15,18]$, mollusks [17], and worms [19]. Recent studies in Drosophila melanogaster have shown that $R$. rosea can also be used as an anti-aging pharmacological agent [7]. The intriguing relationship between aging and stress resistance is increasingly mentioned in contemporary gerontology [20]. Moreover, it was shown that many adaptogens have antiaging properties; conversely, many anti-aging preparations were found to increase adaptive capabilities [21]. It has also been hypothesized that stressed plants can synthesize stress-signaling molecules, which increase stress resistance of herbivorous species [22].

In this study, we pursued several goals. Particularly, we wished to reproduce and confirm previous results $[7,8]$ independently, running experiments in Ukraine on a fruit fly line, caught from nature, and using freshly prepared unprocessed $R$. rosea rhizome. In some cases, especially for the newly discovered preparations, repeated tests in different laboratories are thought to be useful prior to the search for a molecular mechanism [23]. We also tried to validate adaptogenic properties of our rhizome preparations by checking the resistance of flies fed $R$. rosea to potential oxidative stress, exerted by menadione, and heat stress. Along with mobility and fecundity, stress resistance can also be examined as an estimate of life quality'. It is noteworthy that not all life-extending medications can improve healthspan [24], and this may not be acceptable in the medical sense. Thus, checking healthspan indices would be important for recognition of an anti-aging remedy with minimum negative side effects. Here, we present data on the life-long stress resistance of fruit flies fed a diet supplemented with $R$. rosea rhizome powder.

Our last goal was to define optimal dietary conditions for the anti-aging effect of $R$. rosea. This effect can be modulated by different factors, and diet is thought to be one of the most critical. It is well established that diet itself can prolong or shorten lifespan [25]. Recent studies have shown that the median lifespan of a population depends not only on the total caloric value of the diet but also on the dietary composition [26-28], especially the protein-to-carbohydrate ratio [29]. If diet modulates the effect of anti-aging pharmacological intervention, the maximum life-prolonging effect may be seen only for some certain dietary conditions, whereas others might not be so favorable. The same is true for health-promoting effects. The dietary response could also provide some implications for the primary molecular targets of $R$. rosea bioactive compounds, among which salidroside, rosavins, and p-tyrosol are the most studied. In this work, we show how dietary composition may affect life extension and food intake with $R$. rosea supplement.

\section{Results and discussion}

\section{Rhodiola supplementation increases median lifespan}

Previously, it was found that $R$. rosea increased lifespan in fruit flies $[7,8]$. These studies were performed at the University of California in Irvine (UCI) using $R$. rosea powder manufactured and processed in China, and a Drosophila melanogaster line, caught in nature and kept for a long time at the laboratory conditions. In Ukraine, Rhodiola rosea, called 'golden root', is a famous medicinal herb known to increase working capacity, stamina, and health in general. The plant grows predominantly in mountainous areas around $1000 \mathrm{~m}$ above mean sea level. In the Carpathian Mountains, $R$. rosea is relatively accessible, and the fresh roots can be collected. Virtually every year, research teams from medical universities in the West Ukraine publish their results on multiple health benefits provided by administration of $R$. rosea extract in local journals. Here we tried to reproduce experiments conducted previously using freshly prepared roots of $R$. rosea and a wild $D$. melanogaster line collected in western Ukraine.

We have found that supplementation of fruit fly food, containing $5 \%$ yeast and 5\% sucrose, (approximately $6.25 \%$ carbohydrate and $2.25 \%$ protein) with $5.0 \mathrm{mg} / \mathrm{ml}$ and 10.0 $\mathrm{mg} / \mathrm{ml}$ of $R$. rosea rhizome extended the median lifespan of flies of both sexes by $14 \%$ to $17 \%$ (Figure 1, Table 1). The same concentrations of $R$. rosea rhizome increased maximum lifespan of the females by between $3 \%$ and $6 \%$. No significant effects on maximum lifespan were observed in males fed with food supplemented by $R$. rosea in mentioned concentrations. Notably, females and males fed diet supplemented with $2.5 \mathrm{mg} / \mathrm{ml}$ and $30.0 \mathrm{mg} / \mathrm{ml}$ rhizome had, respectively, a $6 \%$ and 15\% lower maximum lifespan, compared with the control. Moreover, $30.0 \mathrm{mg} / \mathrm{ml}$ of $R$. rosea decreased median lifespan by $9 \%$ to $12 \%$ (Table 1 , Figure 1), demonstrating possible toxic effects of the rhizome at the higher concentrations. 

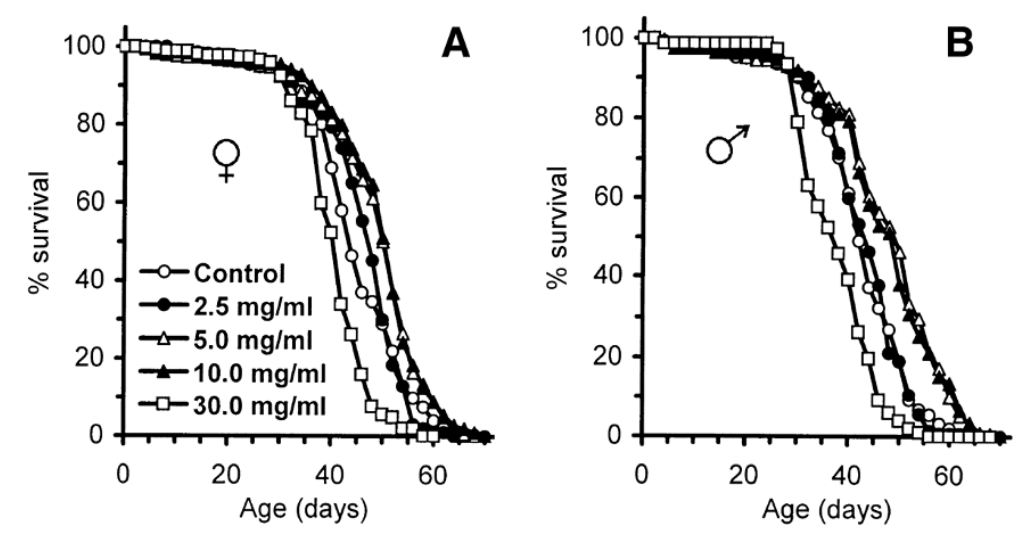

Figure 1 Survivorship of female (A) and male (B) flies fed with different concentrations of $R$. rosea rhizome. Results are representative of three separate experiments with about 100 to 400 flies per sex, per diet.

In previous studies, flies were fed diets containing yeast paste mixed with bioactive compounds from $R$. rosea, as either rhizome powder [7] or standardized rhizome extract [8]. The lifespan-extending concentration of $R$. rosea powder, which did not lead to a significant decrease in fecundity, was $60 \mathrm{mg} / \mathrm{ml}$ powder [7]. When the extract was used, its active concentration was $25 \mathrm{mg}$ of the extract per $1 \mathrm{ml}$ yeast paste; however, $125 \mathrm{mg} / \mathrm{ml}$ extract exhibited a maximum effect. In these experiments, amounts of $R$. rosea powder mixed into fly food were several times smaller, while the highest concentration, $30.0 \mathrm{mg} / \mathrm{ml}$, shortened lifespan. Nevertheless, it is now possible to say that $R$. rosea definitely increases the median lifespan of fruit fly cohorts, regardless of the preparation type, supplementation method, basic diet, or fruit fly line. The maximum increase in mean lifespan, shown in previous studies, was around 30\%. In this study, an increase of up to $17 \%$ was obtained for the diet with $5 \%$ and $5 \%$ sucrose, with $10.0 \mathrm{mg}$ of $R$. rosea rhizome powder per $1 \mathrm{ml}$ of food.

The differences in the lifespan-prolonging effects obtained in previous studies and this one can be related to differences in the method of $R$. rosea supplementation and diet. In particular, the research team in UCI used banana-molasses food, which contains a different set of vitamins and other essential micronutrients than the plain yeast-and-sucrose food used in the current experiments. It is possible that $R$. rosea might prolong lifespan even further in combination with vitamins and other bioactive substances. Moreover, consumption of yeast paste by fruit flies could be less than consumption of ordinary food containing carbohydrates. This could also be the cause of the reductions in fruit fly fecundity with $R$. rosea preparation found in previous studies. It is known that ingestion of yeast influences the amount of eggs laid by female fruit flies $[27,30]$. When yeast and $R$. rosea

Table 1 Lifespan trials of the control flies and flies fed diets supplemented with $R$. rosea rhizome

\begin{tabular}{|c|c|c|c|c|}
\hline Sex & $\begin{array}{l}R \text {. rosea rhizome concentration } \\
(\mathrm{mg} / \mathrm{ml})\end{array}$ & $\begin{array}{l}\text { Median lifespan } \\
\text { (days) }\end{array}$ & $\begin{array}{l}\text { Degree of median lifespan extension or } \\
\text { reduction }(\%)\end{array}$ & $\begin{array}{l}\text { Maximum lifespan } \\
\text { (days) }\end{array}$ \\
\hline \multicolumn{5}{|c|}{ Females } \\
\hline & 0 (control) & 44 & & $61.3 \pm 0.5$ \\
\hline & 2.5 & 47 & +6.8 & $59.5 \pm 0.7$ \\
\hline & 5.0 & $50^{*}$ & +13.6 & $63.4 \pm 0.6^{* *}$ \\
\hline & 10.0 & $50^{*}$ & +13.6 & $63.7 \pm 0.5^{* *}$ \\
\hline & 30.0 & $40^{*}$ & -9.1 & $53.8 \pm 0.4^{* *}$ \\
\hline \multicolumn{5}{|c|}{ Males } \\
\hline & 0 (control) & 42 & & $60.3 \pm 0.6$ \\
\hline & 2.5 & 43 & +2.4 & $56.7 \pm 0.6$ \\
\hline & 5.0 & $49^{*}$ & +16.7 & $64.3 \pm 0.5^{* *}$ \\
\hline & 10.0 & $48^{*}$ & +14.3 & $63.9 \pm 0.4^{* *}$ \\
\hline & 30.0 & $37^{*}$ & -11.9 & $50.4 \pm 0.8^{* *}$ \\
\hline
\end{tabular}

*Significantly different $(P<0.05)$ from control group as evaluated by Wilcoxon rank sum test. **Significantly different in comparison with control according twoway analysis of variance for normal data with Bonferroni correction. 
preparation are combined in one supplement, the preparation might affect consumption of the whole supplement, and even at the level of food choice. In this study, we have suggested that $R$. rosea might influence food consumption and in this way regulate lifespan.

\section{Rhodiola decreases food consumption in fruit flies}

Food intake was assessed in 6- and 16-day-old females by the amount of food dye, erioglaucine, ingested within 15 min intervals. Six-day-old flies kept on Rhodiolasupplemented food did not show significant difference in food consumption as compared with control flies (Figure 2), while 16-day-old individuals fed food supplemented by 5.0 $\mathrm{mg} / \mathrm{ml}$ Rhodiola rhizome consumed 1.4-, 1.8-, and 3.1-fold less food than controls on diets containing $5 \%, 10 \%$, and $15 \%$ yeast and sucrose, respectively. However, addition of $30.0 \mathrm{mg} / \mathrm{ml}$ of Rhodiola supplement led to a halving in ingestion of the food containing 5\% yeast and 5\% sucrose. Alternatively, feeding was quantified by counting the flies sitting on the food surface directly, as described in [31]. The percentage of flies on the surface of the media with their proboscis extended and touching the food was significantly lower when food was supplemented with $5.0 \mathrm{mg} / \mathrm{ml}$ Rhodiola (Additional file 1: Figure S1). Thus, a reduced intake of yeast paste in previous studies could be the reason for reduced fecundity, despite it having been shown previously that the influence of $R$. rosea on yeast consumption is not significant [7].

It was shown that feeding behavior of $D$. melanogaster is regulated by many mechanisms, including the TOR pathway and its target S6 kinase, the insulin signaling pathway, and developmental hormones. It was recently shown that feeding behavior of D. melanogaster larvae could be regulated by S6 kinase, the downstream target of TOR and phosphoinositide-dependent kinases [32]. Larvae with up-regulated S6K consumed less food. However, a decrease in food consumption, conferred by $R$. rosea preparation, implies activation of S6 kinase [32],
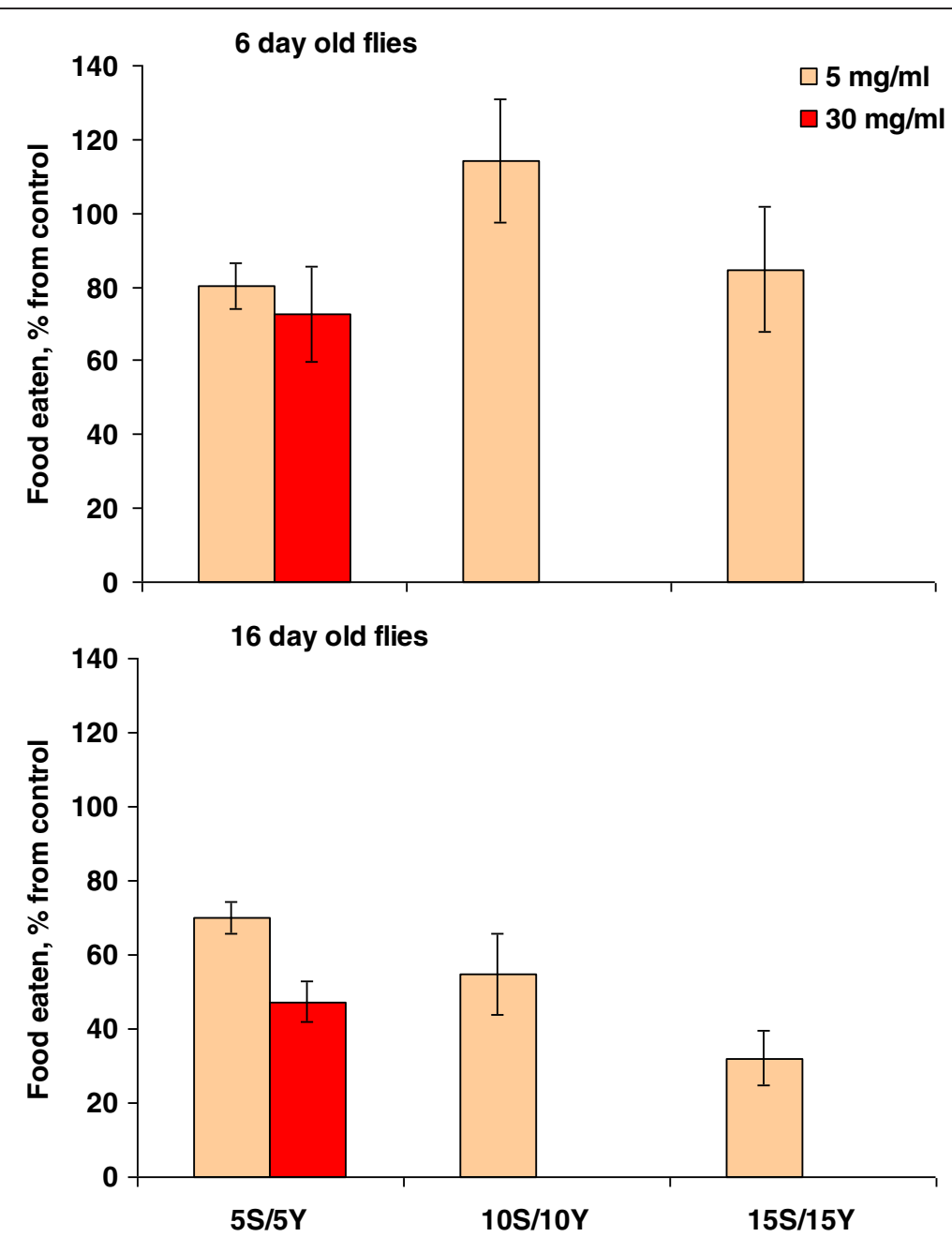

Figure 2 Effect of $R$. rosea supplement on food consumption rate. The difference between 6- and 16-day-old females is significant with $P<0.05$ on 5S:5Y and 15S:15Y diets as evaluated by Student's $t$ test. 
and, hence, activated TOR kinase. In turn, S6 kinase may inhibit the insulin signaling pathway by phosphorylation of insulin receptor substrate, thus promoting activity of transcriptional factor FOXO (forkhead box $\mathrm{O}$ ) [33]. It was found that DAF-16, the FOXO homolog in C. elegans, might be involved in the life-prolonging effect of $R$. rosea preparations [19]. There are also other regulators of food intake; one of these is the juvenile hormone-binding protein Takeout [34]. It is known that Takeout mutation results in the increased food ingestion. However, Takeout has been shown to regulate feeding time, rather than ingestion rate [31].

Food intake in $D$. melanogaster is also regulated by biogenic amines, particularly by serotonin or octopamine [35]. Increased serotonin concentration is considered a satiety signal [36] and inhibits food consumption in insects [37]. It was also suggested that serotonin and octopamine might regulate insulin secretion by insulin-producing cells in Drosophila brain [36,38], thus potentially influencing the insulin signaling pathway. This explanation seems plausible, since $R$. rosea rhizome contains many compounds, such as kaempferol [15], found as inhibitors of monoamine oxidase, an enzyme catalyzing oxidation of biogenic amines [39]. Moreover, it was shown that $R$. rosea preparations are able to inhibit monoamine oxidase [40]. On the other hand, some monoamine oxidase inhibitors, as well as some monoamines themselves [41], were shown to extend lifespan [42].

Notably, our data have shown that $R$. rosea does not extend lifespan as much as the mth or chico mutations $[43,44]$, or other compounds, for example, 4-phenylbutyrate [3]. In this case, it would be interesting to know which age stratum of individuals would benefit most from the $R$. rosea treatment. Pursuing the latter goal, we have analyzed Gompertz equation parameters as the next step.

\section{Consumption of Rhodiola preparation causes changes in age-independent and age-dependent mortalities}

A model described by the Gompertz equation is a simple method to analyze survival data. This equation is

$$
\mu(t)=A e^{\alpha t}
$$

where $\mu(t)$ is the age-specific mortality rate, $t$ is the age, $A$ is the age-independent parameter and $\alpha$ is the agedependent parameter. The higher $A$ and $\alpha$, the higher will be the mortality rate and, hence, the shorter the median and maximum lifespans. Age-independent mortality is thought to be caused by environmental factors or by genes responsible for early-age death [45].

We found that $R$. rosea lowered age-independent mortality in females, but slightly increased it in males (Figure 3). Moreover, males had higher $A$ estimates than females, regardless of the preparation presence. However, it seems that, unlike females, the lifespan extension in males was provided by lowering the age-dependent mortality.

In our understanding, the estimates $A$ and $\alpha$ are not related precisely to the aging process itself, and tell us nothing about the rate of physiological changes in an individual. Nevertheless, these parameters could be examined as a good quantitative representation of the most susceptible age stratum in the cohort. For instance, a high $A$ value would indicate accelerated dying among young individuals, while a high $\alpha$ would indicate quick dying in a group of older individuals, which, in our case, constitutes more than $90 \%$ of the whole cohort at the time of its half-life. Thus, in this case, we could suppose that the action of $R$. rosea might depend on the physiological state of the organism, accelerating the death of the least robust organisms, supporting survival of the organisms with a moderate robustness, and not influencing the most robust individuals. This approach partly explains why $R$. rosea supports survival of 'young' female Drosophila, suggesting that they are more resistant to environmental perturbations than males of the same age. It was also reported previously that females live longer and are more resistant to different stresses than male flies [46].

As a next step, we checked 'life-quality' indices, conventionally measured for Drosophila and other animal models of aging. Since $R$. rosea is known mainly by its adaptogenic properties, we also checked age-related changes in stress resistance of the treated flies.

\section{$R$. rosea supplementation increases climbing activity, heat, and oxidative stress resistance}

Climbing activity is considered as a marker of healthspan in Drosophila [47]. The association of a decline in climbing activity with age has been established in $D$. melanogaster. We observed that $R$. rosea improved climbing activity of the flies over a wide concentration range. Rhodiola-fed flies showed significantly higher climbing activity from day 16 to day 40 compared with the controls. On day 33, 36-55\% of females supplemented with $2.5 \mathrm{mg} / \mathrm{ml}, 5.0 \mathrm{mg} / \mathrm{ml}$, and $10.0 \mathrm{mg} / \mathrm{ml}$ of $R$. rosea rhizome were able to pass $5 \mathrm{~cm}$ distance from food surface within 20 seconds, while among control flies only $10 \%$ could fulfill this task (Figure 4A, Table 2). Males showed similar results, with the strongest effect at $10.0 \mathrm{mg} / \mathrm{ml} R$. rosea rhizome (Figure 4B, Table 2).

Many studies suggest a link between aging and stress resistance $[19,20,48]$. In this study, $R$. rosea rhizome conferred resistance to heat shock and menadione-induced stress. The newly enclosed and older (up to day 34 ) flies of both sexes did not demonstrate any difference between control and Rhodiola-fed groups in heat-induced coma onset (Figure 5). However, 34-day-old males, fed with the 


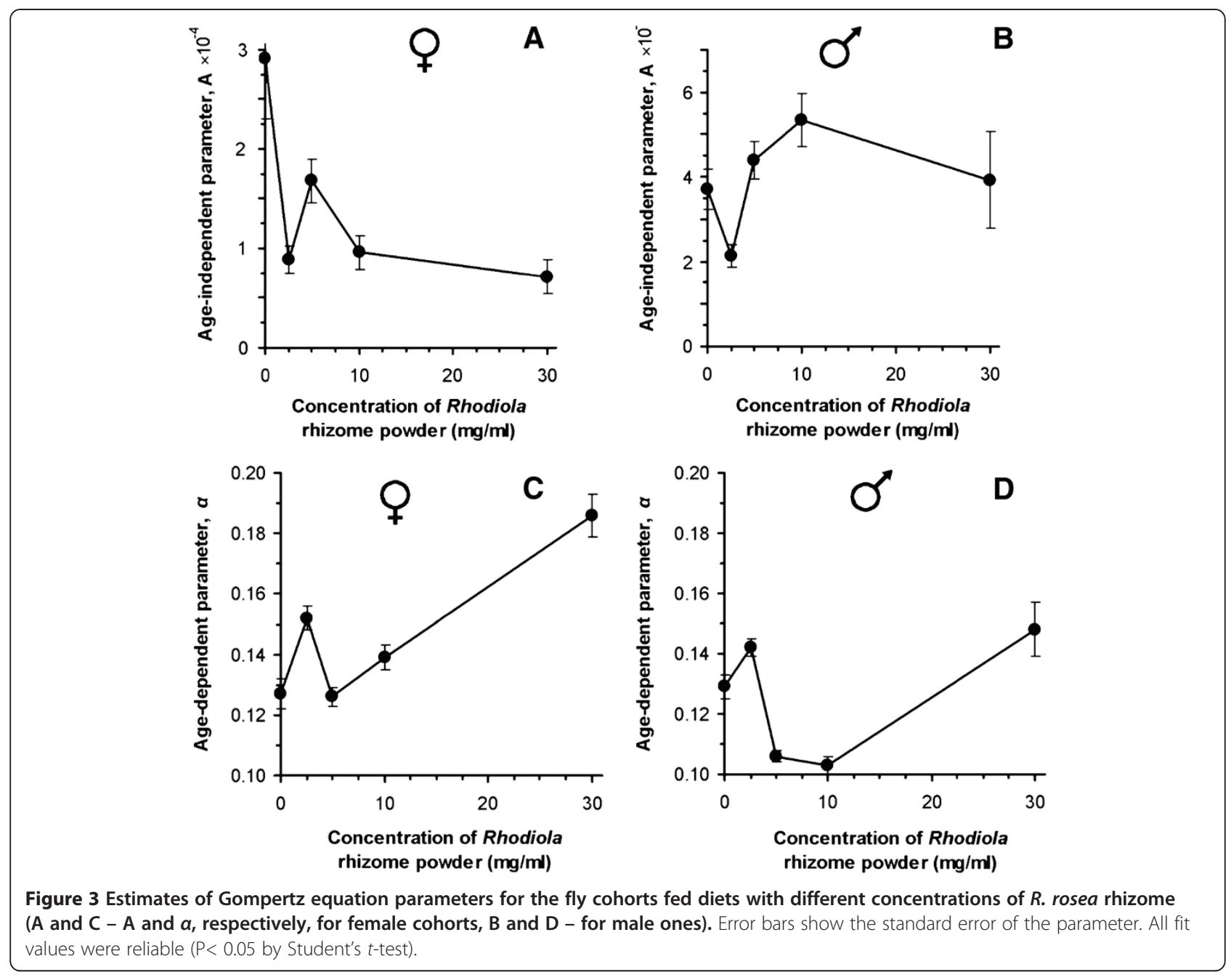

food supplemented with $5.0 \mathrm{mg} / \mathrm{ml}$ and $10.0 \mathrm{mg} / \mathrm{ml} R$. rosea rhizome had a 1.8- and 2.5-fold longer recovery time, than controls, respectively (Figure 5B). Compared with controls, 34-day-old females supplemented with $2.5 \mathrm{mg} / \mathrm{ml}, 5.0$ $\mathrm{mg} / \mathrm{ml}$, and $10.0 \mathrm{mg} / \mathrm{ml}$ of $R$. rosea rhizome recovered from heat coma 1.4-, 2.1-, and 1.6-fold faster, respectively
(Figure 5C). Among males, only those receiving the 5.0 $\mathrm{mg} / \mathrm{ml} R$. rosea rhizome, recovered faster (2.6-times) from heat coma than the controls.

Recent studies have shown that heat-shock proteins (HSP) are involved in lifespan extension. In particular, Rhodiola preparations increased levels of HSP-16 in $C$.
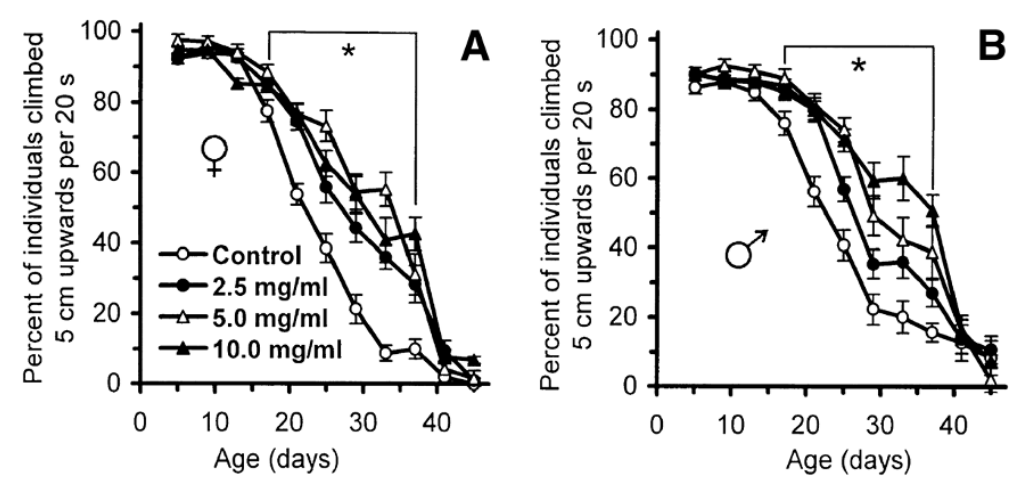

Figure 4 Climbing activity of (A) female and (B) male flies fed by food with different concentrations of $R$. rosea rhizome. Results are representative of two independent experiments. *Significantly different $(P<0.05)$ from control group as evaluated by Dunnett's test. 
Table 2 Induced climbing activity of the control flies and flies fed food supplemented with $R$. rosea rhizome

\begin{tabular}{lccc}
\hline Sex & $\begin{array}{c}\text { R. rosea rhizome } \\
\text { concentration } \\
\text { ( } \mathbf{m g} / \mathbf{m l})\end{array}$ & $\begin{array}{c}\text { Induced } \\
\text { climbing activity } \\
\text { at day 33 (\%) }\end{array}$ & $\begin{array}{c}\text { Induced } \\
\text { climbing activity } \\
\text { at day 45 (\%) }\end{array}$ \\
\hline Females & & \\
\hline 0 (control) & $9 \pm 2$ & 0 \\
\hline 2.5 & $36 \pm 3^{*}$ & $1 \pm 1$ \\
\hline 5.0 & $55 \pm 6^{*}$ & $2 \pm 1$ \\
\hline 10.0 & $41 \pm 5^{*}$ & $7 \pm 2$ \\
\hline Males & & \\
\hline & 0 (control) & $20 \pm 5$ & $8 \pm 5$ \\
\hline 2.5 & $36 \pm 5^{*}$ & $11 \pm 4$ \\
\hline 5.0 & $42 \pm 6^{*}$ & $2 \pm 2$ \\
\hline 10.0 & $60 \pm 7^{*}$ & $7 \pm 4$
\end{tabular}

*Significantly different $(P<0.05)$ from control group as evaluated by Dunnett's test. elegans [19]. Lifespan extension in D. melanogaster was also associated with enhanced Hsp22 levels [49,50]. It is known that Hsp22 is synthesized after a rapid heat shock [51] and may be important for cell survival under this stress. Kurapati and colleagues [49] showed that the level of Hsp22 mRNA was increased in both long- and shortlived lines between days 40 and 50, but later the expression of this gene was decreased. In this study, we used a rapid exposure to high temperature and observed that the flies fed the diet supplemented with $R$. rosea rhizome powder were more resistant to heat shock at the middle of the cohort lifetime.

Menadione (synthetic provitamin K) is a compound that produces superoxide-anion in a redox-cycling way [52]. In this study, an age-dependent change in menadione sensitivity was observed for both males and females (Figure 6). Among young flies ( $<16$ days), no significant difference in sensitivity was observed between control and Rhodiola-fed groups exposed to $20 \mathrm{mM}$ menadione, whereas older flies fed the herb preparation were more resistant. A 2.3-fold
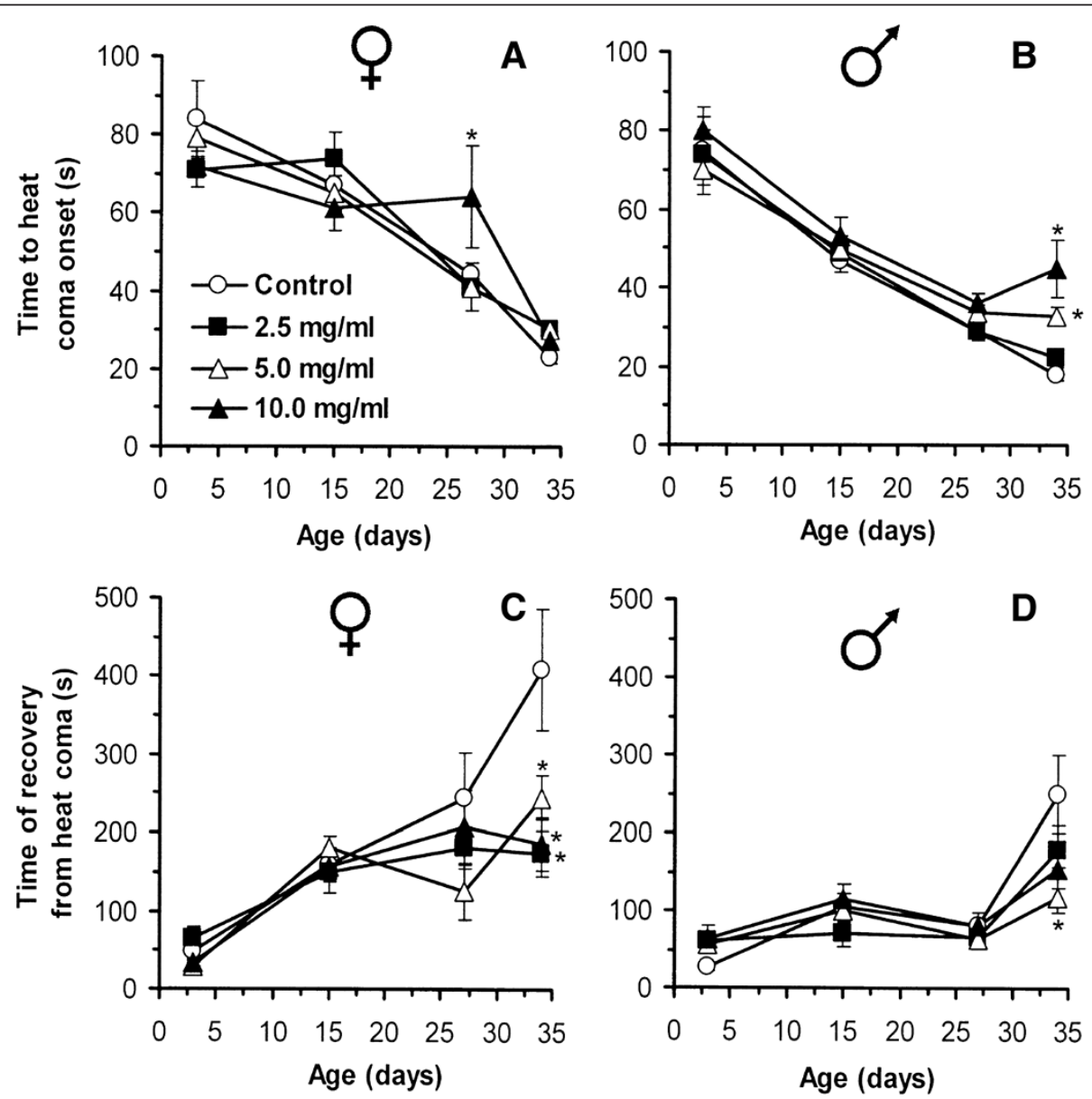

Figure 5 Time of heat coma onset (A and B for females and males, respectively) and recovery (C and D for females and males, respectively) for flies fed food with different concentrations of $\boldsymbol{R}$. rosea rhizome. Results are representative of four independent experiments. *Significantly different $(P<0.05)$ from control group as evaluated by Dunnett's test. 

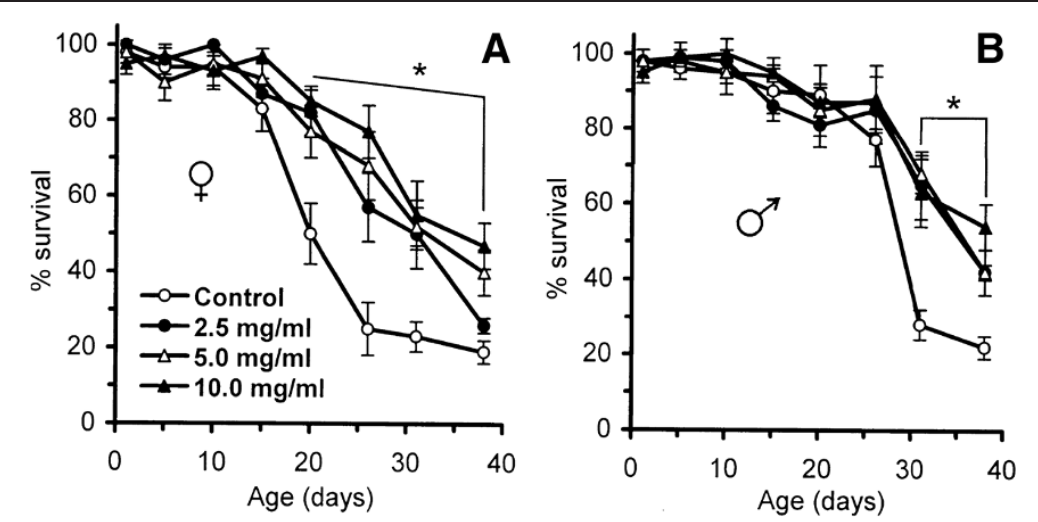

Figure 6 Survival of (A) female and (B) male flies fed with different concentrations of $R$. rosea rhizome after exposure to $20 \mathrm{mM}$ menadione. Groups of flies of the indicated ages were taken from the cohorts and transferred to the vials with paper soaked in a solution containing 5\% sucrose and $20 \mathrm{mM}$ menadione sodium bisulfite. The percentage of survivors was determined after $24 \mathrm{~h}$. Results are representative of four independent experiments. *Significantly different $(P<0.05)$ from control group as evaluated by Dunnett's test.

higher resistance was observed in 31-day-old males (Figure 6B) and a 2.4-fold higher resistance was observed in 20-day-old females (Figure 6A). The difference among treated groups $(2.5 \mathrm{mg} / \mathrm{ml}, 5.0 \mathrm{mg} / \mathrm{ml}$, and $10.0 \mathrm{mg} / \mathrm{ml} R$. rosea rhizome) was not statistically significant.

It was previously shown that treatment of pond snail Limnaea stagnalis larvae by $R$. rosea extract conferred resistance to both $600 \mu \mathrm{M}$ menadione and heat shock under $43^{\circ} \mathrm{C}$ [17]. Later, it was shown on C. elegans that adaptogens, including $R$. rosea, activate DAF-16/FOXO transcription factor, promoting change of its intracellular localization. In another study, performed on bladder cancer cell lines, $R$. rosea extract and salidroside itself increased phosphorylation of AMP-activated protein kinase, leading, most probably, to the activation of mTOR pathway [53]. It is known that both FOXO and TOR pathways are referred to stress resistance. In particular, one of the FOXO downstream targets is manganesecontaining superoxide dismutase [54], which is responsible for elimination of mitochondrial superoxide and probably capable of providing a defense against redoxcycling agents, such as menadione or paraquat. However, it was found that $R$. rosea did not activate antioxidant responses in human osteosarcoma-derived diploid fibroblast and neuroblastoma cell lines [55]. In general, the findings on activation of HSP or antioxidant defenses by $R$. rosea are controversial. They imply that influence of $R$. rosea on signaling pathways is either transient, or that it does not operate directly with reactive oxygen species, but rather promotes more effective elimination of oxidized molecules (for example, autophagy).

\section{$R$. rosea supplementation enhances fly fecundity}

Many conditions, mutations, and compounds that prolong lifespan may reduce reproduction [56]. From a medical and ethical point of view, lifespan extension at a cost of reduced reproduction would not be acceptable for the human population. In this context, there is a clear contemporary trend in searching for anti-aging remedies that do not affect reproduction [56]. This point seemed to us reasonable in the actual experiments. In previous studies, high doses of $R$. rosea powder or extract decreased egg-laying ability of fruit flies $[7,8]$. We checked the same for the preparation of $R$. rosea, collected in the Ukrainian Carpathian Mountains.

A gradual decrease in fecundity with age in all treatment groups was observed, but $R$. rosea rhizome enhanced the fecundity in most age groups (Figure 7). The flies fed a diet supplemented with $R$. rosea rhizome demonstrated a higher fecundity on days $3(2.5 \mathrm{mg} / \mathrm{ml}), 7$ (all concentrations), 9 (10.0 mg/ml), 11 (all concentrations), 15, and 19 $(10.0 \mathrm{mg} / \mathrm{ml})$. It seems that $R$. rosea rhizome at 2.5 and 5.0 $\mathrm{mg} / \mathrm{ml}$ provided a higher fecundity in young flies until approximately day 11 , while $10.0 \mathrm{mg} / \mathrm{ml}$ of $R$. rosea rhizome enhanced fecundity from day 7 until day 19. The maximum effect was found at $10.0 \mathrm{mg} / \mathrm{ml}$. There was found to be a positive relationship between fly fecundity and supplementation with $10.0 \mathrm{mg} / \mathrm{ml} R$. rosea (the point-biserial correlation coefficient was equal 0.38 with $P=0.0033$ ).

To investigate the possible positive effect of $R$. rosea preparation on the egg-laying ability of female Drosophila, we measured the mating speed and duration of copulation in the control and Rhodiola-treated flies. These parameters, as well as the percentage of mated females and copulated flies, were not significantly different at any concentration of Rhodiola rhizome used (Figure 8). The number of eclosed offspring was also not affected.

A decrease in fecundity is often considered to be due to caloric restriction. Current data on fecundity suggest that $R$. rosea preparation might not mimic calorie restriction. All our observations on fecundity partially support the assumption that $R$. rosea may preserve biogenic amines from 


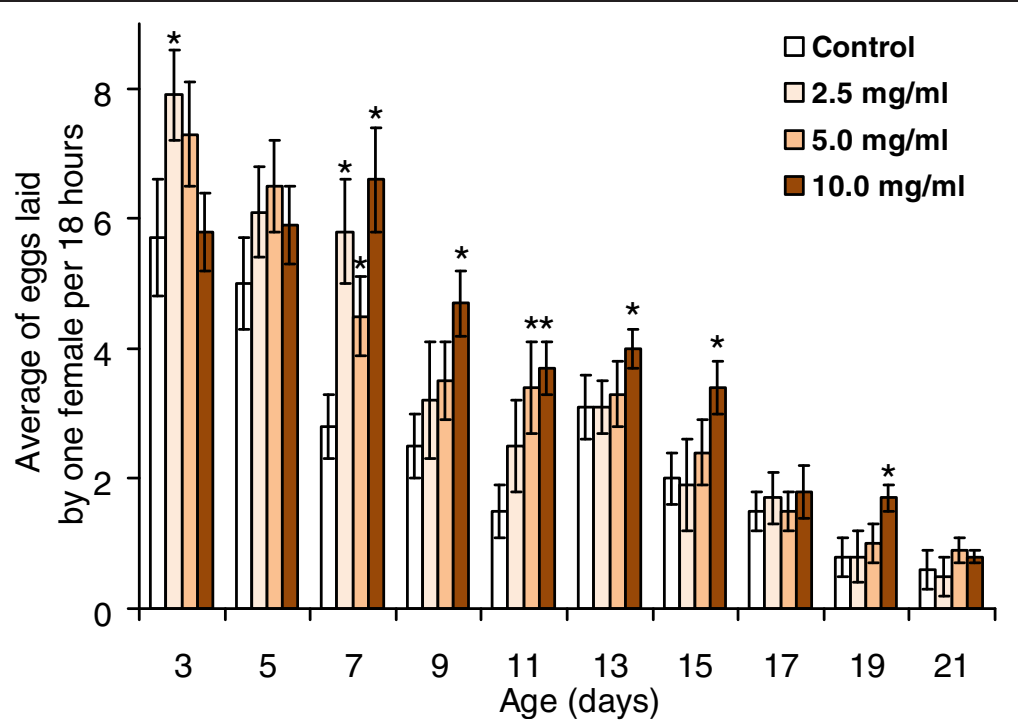

Figure 7 Fecundity of flies fed with different concentrations of $R$. rosea rhizome supplement at different ages. * Significantly different $(P<0.05)$ from control group as evaluated by Dunnett's test.

oxidation by inhibition of monoamine oxidase. In particular, it has recently been shown that octopamine is required for egg release from ovary [57], while serotonin is needed for male ejaculation [58].

\section{Effects of protein-to-carbohydrate ratio on the lifespan extension by Rhodiola}

Recent studies have shown that bioactive compounds of $R$. rosea, particularly salidroside, may affect the mTOR (mammalian target of rapamycin) pathway [53]. It is known, that dietary protein-to-carbohydrate (P:C) ratio influences TOR signaling in D. melanogaster [29] and hence, lifespan, stress resistance, and food consumption [13]. In this way, a specific diet could modulate the lifespanprolonging effect of $R$. rosea. In this study, we conducted a pilot experiment assessing lifespan extension by $R$. rosea on eight diets with different P:C ratios. The lifespan assays were conducted using mortality cages [59]. Yeast was used as the protein source, while sucrose was used as the carbohydrate source.

We obtained similar results on the diet with composition close to the one described previously. Diet-response surfaces show that the highest median lifespan was reached on diets with a P:C ratio around 0.36 for the diet with $5 \mathrm{~g} / \mathrm{l}$ yeast and sucrose (Figure 9, A and B). These data converge with those described by Skorupa et al. [28]. However, the environment, namely the vials or mortality cage, as well as peculiarities of protein and micronutrient source, might also influence lifespan parameters. In particular, in our previous study, fruit flies lived approximately 80 days in vials on the diet with $10 \%$ sucrose with only $0.25 \%$ yeast extract [60], whereas in this study, fruit flies lived around 30 days in cages on a similar diet, $(0.25 \%$ yeast, $10 \%$ sucrose; corresponding to around $10.1 \%$ carbohydrates and $0.11 \%$ protein).

Rhizome powder of $R$. rosea added to the diet at a concentration of $5 \mathrm{mg} / \mathrm{ml}$ extended mean lifespan by up to $11 \%$ to $15 \%$ on diets with P:C ratios of $0.044,0.2$, and 0.36 , except the diet with $15 \%$ yeast and sucrose (15Y:15S), and up to $21 \%$ on the diet with P:C ratio 0.011 (Figure 9C). However, there was no significant extension on the diets with P:C ratios 1 (less than 9\%) and 0.36 (15Y:15S), while on the diet with a P:C ratio 1.5 (5Y:0.25S) $R$. rosea supplementation decreased lifespan by about $10 \%$.

These data lead us to suggest that the macronutrients, being at high concentration in the food, may cancel out the beneficial effect of $R$. rosea on Drosophila lifespan. This effect seems to be caused by the increased amount of protein in the diet. Additionally, the P:C ratio along with food consumption should also be taken into account.

\section{Conclusions}

Our current data indicate that $R$. rosea from the Carpathian Mountains increases lifespan and improves healthspan in a fruit fly line caught in the same region. However, the lifespan-prolonging effect of $R$. rosea on the fruit fly depends on the protein-to-carbohydrate ratio fed to it. Diets with high protein-to-carbohydrate ratios or high caloricity do not support the beneficial action of $R$. rosea on longevity. We also demonstrated that lifespan extension by $R$. rosea might depend on the physiological state of organism, being beneficial for individuals with moderate robustness. The maximum anti-stress effect of $R$. rosea is also observed for individuals with ages close to the half-life of the cohort. 

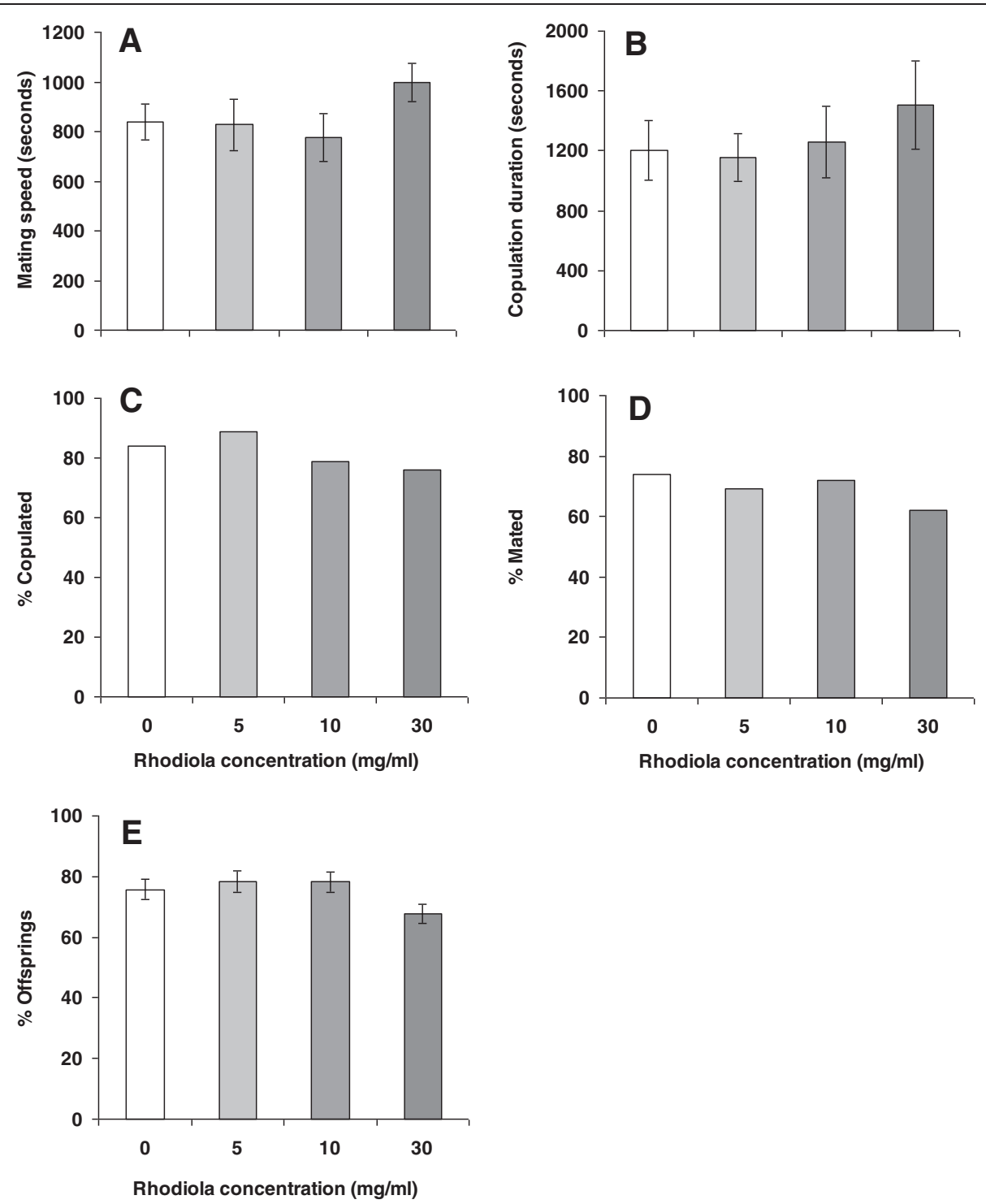

Figure 8 Mating speed (A), copulation duration (B), percentages of copulated pairs (C) and mated females (D), and number of flies eclosed from eggs (E) for flies fed with control food or with food supplemented by $5 \mathrm{mg} / \mathrm{ml}$ Rhodiola rhizome. Significance of difference between groups was assessed using Student's $t$ test.

In addition to lifespan extension, $R$, rosea retards agedependent decline in 'life-quality' indices of aged $D$. melanogaster individuals, such as climbing activity. The preparation from Carpathian $R$. rosea used in our study also has a positive effect on fruit fly egg-laying ability.

Although our work mainly supports previous reports on the anti-aging effects of $R$. rosea preparations, more work is needed to optimize dosage, evaluate its anti-aging effects on other model organisms, such as mammals, and identify putative and active compounds of $R$. rosea that might provide an opportunity to decipher the molecular mechanisms of Rhodiola components. Current data on these mechanisms remain controversial, suggesting involvement of the key regulators of longevity and stress resistance, namely transcription factor FOXO and TOR kinase. However, all molecular studies were performed on different models. We suppose that these mechanisms differ in unicellular and multicellular organisms, as well as in cell cultures, most of which are derived from tumors. The difference may be between simplistic organisms, like fruit flies or nematodes, and organisms with highly developed hormonal system, like mammals. Thus, future research foresees a molecular approach, beginning with unicellular organisms and purified bioactive compounds of $R$. rosea, and ending up with vertebrate models, close to human beings. 

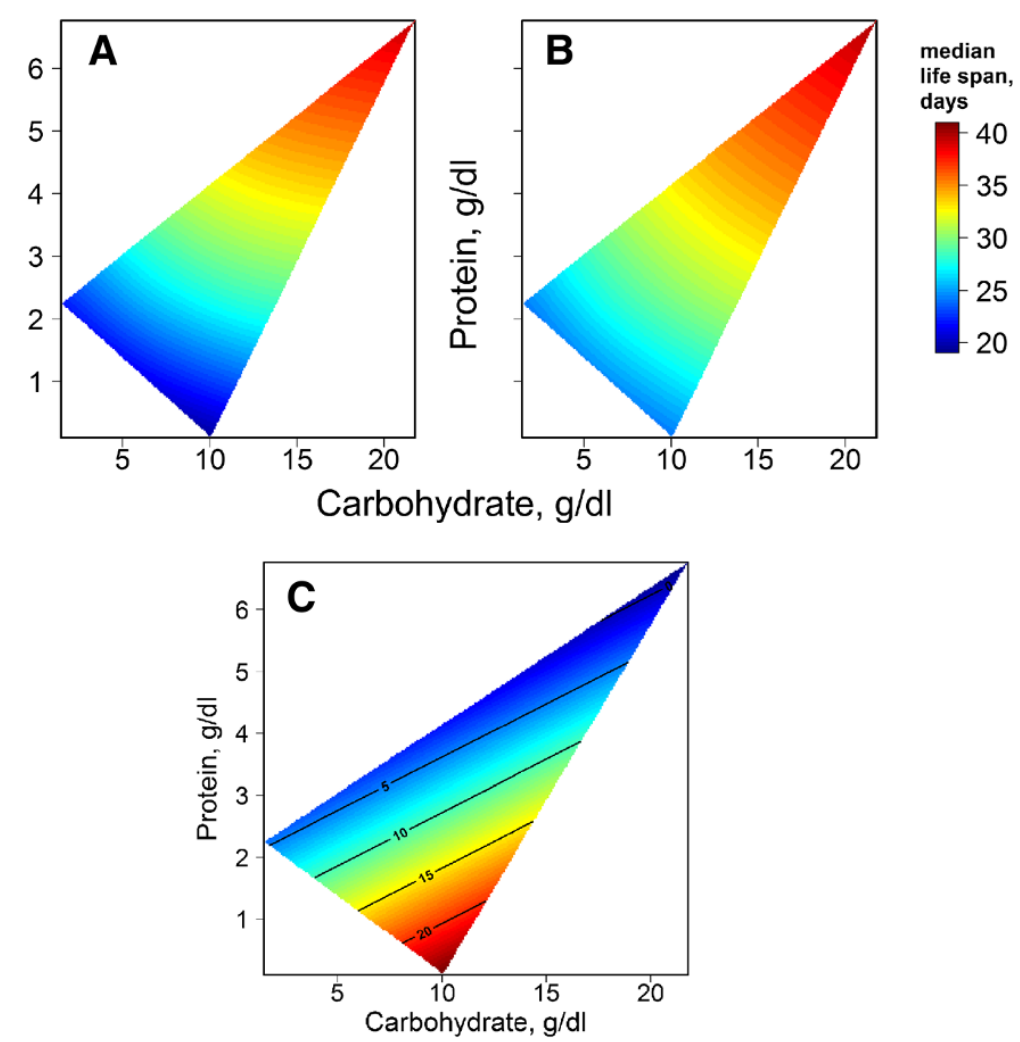

Figure 9 Effect of protein-to-carbohydrate ratio (P:C) on lifespan extension by $\boldsymbol{R}$. rosea rhizome preparation. $\mathbf{A}$, mean lifespan of females fed with control diets with different P:C ratios; $\mathbf{B}$, mean lifespan of females fed diets with different P:C ratios and additionally supplemented with $5 \mathrm{mg} / \mathrm{ml}$ R. rosea rhizome powder; $\mathbf{C}$, percent of lifespan extension by $R$. rosea on diets with different P:C ratios.

\section{Methods}

\section{Drosophila stock and media}

Founder flies (called 'IF') were collected in the southeast part of Ivano-Frankivsk (Western Ukraine) in August 2007. For the present investigations, the 20th and further generations from founder flies were used. General stocks were reared on a medium containing $5 \%$ molasses, $6 \%$ baker's yeast and $1.3 \%$ agar-agar. For mold growth inhibition, the medium was supplemented by $0.4 \%$ propionic acid. Experimental food contained 5\% sucrose and yeast and was solidified with $1.5 \%$ of agar. Rhizomes of $R$. rosea (collected in the Ukrainian Carpathian Mountains near Lazeshchyna) were finely ground and added to experimental food in concentrations of 2.5, 5.0, 10.0, and $30.0 \mathrm{mg} / \mathrm{ml}$. Flies were reared at $25^{\circ} \mathrm{C}$ with a $12: 12$ light-dark cycle and a humidity of about $60 \%$. All components of the fly food were taken from local manufacturers. Among them, propionic acid was of analytical grade.

\section{Rhodiola rosea preparation}

Alkemists Pharmaceuticals (Costa Mesa, CA) characterized our $R$. rosea rhizome powder using high-performance liquid chromatography (HPLC). According to all animal and clinical studies, extracts of $R$. rosea should be standardized to greater than $1.5 \%$ salidroside and about $3 \%$ total rosavins (rosavin, rosarin, and rosin). The HPLC of our rhizome powder showed $1.9 \%$ salidroside and $2.5 \%$ total rosavins.

\section{Lifespan assay}

Mated flies were separated and transferred into glass vials $(15 \times 150 \mathrm{~mm})$ containing $1.25 \mathrm{ml}$ of the experimental food. Each vial contained ten flies. Flies were transferred to vials with fresh food every other day and survivors were counted. Survival curves show means (by each time point) from three independent lifespan tests, in which about 150 to 400 flies of every sex for each concentration of $R$. rosea rhizome powder were used. Maximum lifespan was defined as the mean lifespan of the last $10 \%$ survivors. Survivorship curves were fitted by the equation:

$$
N_{t}=N_{0} \cdot \exp \left\{\frac{A(1-\exp (\alpha t))}{\alpha}\right\}
$$

[61], where $N_{\mathrm{t}}$ is the number of live individuals at any time, $N_{0}$ is the initial cohort size, $A$ is the age-independent parameter of the Gompertz equation, and $\alpha$ is the age- 
dependent parameter of the Gompertz equation. R-project software (version 2.9.2) with the package minpack.lm was used for the calculation of Gompertz equation parameters from this function minimized by Levenberg-Marquardt method.

\section{Dietary response experiments}

Diets with different concentrations (in $\mathrm{g} / \mathrm{dl}$ ) of yeast $(\mathrm{Y})$ and sucrose (S) were used: 0.25Y:10S, 1Y:10S, 5Y:0.25S, 5Y:1S, 5Y:5S, 5Y:10S, 10Y:10S, 15Y:15S. Food was solidified with $1.5 \%$ agar and preserved from mold growth by $0.4 \%$ propionic acid. Cages were made from $15-\mathrm{cm}$ diameter pipe. A plastic vial with food was screwed to the cage through a hole in the sidewall. The number of dead flies was checked every second day. Dead individuals were sucked out by an aspirator through the rubber-covered hole on the sidewall opposite to the food vial hole.

Diet-response surfaces were visualized by non-parametric thin splines using the fields package in $\mathrm{R}$ (version 2.14.1).

\section{Food consumption assay}

Food consumption was measured as described by Lushchak et al. [62] with the following modifications. Groups of ten flies fed each particular diet were placed for $15 \mathrm{~min}$ on the same food with $0.5 \%$ food dye erioglaucine. After feeding, each group of flies was immediately frozen in liquid nitrogen. The flies were then homogenized in $100 \mu \mathrm{l}$ of $50 \mathrm{mM}$ potassium phosphate buffer $(\mathrm{pH} 7.5)$ and centrifuged at 13,500 $\mathrm{g}$ for $15 \mathrm{~min}$, and the supernatant was transferred to a new tube containing $100 \mu$ of the buffer for dilution. Diluted samples were measured in a 96 -well microplate reader at $629 \mathrm{~nm}$. A solution of dye diluted in $50 \mathrm{mM}$ potassium phosphate buffer was used to build a calibration curve. The optical density of the homogenates from flies consuming corresponding diets without the dye was used as a blank. Alternatively, fly feeding was quantified by direct observation, as described in [31].

\section{Physiology assays}

To assess fruit fly fecundity, one male and one female fly were reared in small vials $(15 \times 60 \mathrm{~mm})$ with $0.7 \mathrm{ml}$ of experimental food with or without $R$. rosea rhizome supplement. Food was changed every other day. The number of eggs laid by one female was determined at $18 \mathrm{~h}$ after fly transfer on fresh food. Each bar on the histogram represents a mean \pm standard error of the mean (SEM) from the values obtained from 25 fly pairs for each concentration of $R$. rosea rhizome.

The mating speed, copulation duration, percentage of copulated flies and number of mated females were determined by the protocol described by Chadha [63].

To test climbing activity, ten flies of respective age were gently tapped to the bottom of the vial. After 20 seconds, the percentage of flies that passed a distance of
$5 \mathrm{~cm}$ was counted. Each point of the curve represents a mean \pm SEM from 24 values collected at two independent measurements. The measurement was routinely conducted for 12 vials with eight to ten experimental flies per dose of $R$. rosea root powder, per sex. Each vial was tested three times at each time point and mean values were calculated.

To determine menadione resistance, ten flies were transferred every fifth or sixth day into empty vials for $4 \mathrm{~h}$ of starvation. After starvation, flies were transferred into vials containing folded and rammed strips $(2.4 \times 12 \mathrm{~cm})$ of four-layer cellulose filter paper soaked with $0.8 \mathrm{ml}$ of 20 $\mathrm{mM}$ menadione sodium bisulfite (Sigma-Aldrich Co.) in $5 \%$ sucrose solution. Survivors were counted after $24 \mathrm{~h}$ of exposure.

To evaluate resistance to heat stress, single flies were transferred into small glass vials with cotton stoppers. Vials were incubated in a water bath adjusted to $43^{\circ} \mathrm{C}$. The time to onset of heat knock-down and the time to full restoration of mobility were recorded.

\section{Statistical analysis}

Comparison of survivorship was performed by Wilcoxon rank sum test using R-project software with the package exactRankTests. Climbing activity, oxidative stress, and heat-shock resistance, as well as fecundity data were analyzed using Dunnett's test. Data from all other assays were compared by Student's $t$-test.

\section{Additional file}

\begin{abstract}
Additional file 1: Figure S1. Feeding rates of female Drosophila on food media with different nutrient concentrations and supplemented with $R$. rosea. Feeding rates were recorded by direct observation as the proportion of time flies spent on the surface of the media with their proboscis extended and touching the food. Replicate measurements of the proportion of females feeding versus those not feeding were recorded during a $2-h$ period on the days shown. Significant differences were seen between flies fed the control diet (upper panel) and the diet supplemented with $5.0 \mathrm{mg} / \mathrm{ml}$ R. rosea (lower panel).
\end{abstract}

\section{Abbreviations}

AMPK: AMP-activated protein kinase; FOXO: forkhead box O; HPLC: highperformance liquid chromatography; HSP: heat-shock proteins; mTOR: mammalian target of rapamycin; P:C: protein-to-carbohydrate ratio; SEM: standard error of the mean; TOR: target of rapamycin.

\section{Competing interests}

The authors declare that they have no competing interests.

\section{Authors' contributions}

DVG performed the fecundity assay, participated in the lifespan, climbing activity, and menadione resistance assays, analyzed the Gompertz equation estimates, diet response surfaces and the fecundity and heat-shock resistance data, wrote the manuscript draft, and edited all its subsequent versions. ISY performed dietary response and food consumption assays. VIL co-designed research, critically discussed data, and co-edited the manuscript. MJ arranged HPLC analysis for rhizome of Carpathian R. rosea, made critical remarks on data performance, and co-edited the manuscript. OVL designed research, governed all assays, took part in lifespan, climbing activity, 
menadione and heat-shock resistance assays, analyzed lifespan, climbing activity, menadione resistance data, and co-edited the final version of the manuscript. All authors read and approved the final manuscript.

\section{Acknowledgements}

We are grateful to B Rovenko, A Gloviak, M Zhdanyuk, K Koturbash, and N Perkhulyn for technical assistance in experiments and Dr. Mike Gerards for improvements to the quality of our written English. In addition, we are grateful to Katharine M Mullen for the help in the curve-fitting procedure using the minpack.Im package. We also thank Professor Thomas B Kirkwood for sharing reprint versions of his manuscripts.

\section{Author details}

'Department of Biochemistry and Biotechnology, Vassyl Stefanyk Precarpathian National University, Ivano-Frankivsk 76025 Ukraine. ${ }^{2}$ Department of Pharmaceutical Sciences, University of California, Irvine, CA 92697 USA. ${ }^{3}$ Department of Zoology, Stockholm University, S-10691 Stockholm, Sweden.

Received: 19 April 2012 Accepted: 11 February 2013 Published: 2 April 2013

\section{References}

1. Bass TM, Weinkove D, Houthoofd K, Gems D, Partridge L: Effects of resveratrol on lifespan in Drosophila melanogaster and Caenorhabditis elegans. Mech Ageing Dev 2007, 128:546-552.

2. Wang C, Wheeler CT, Alberico T, Sun X, Seeberger J, Laslo M, Spangler E, Kern B, de Cabo R, Zou S: The effect of resveratrol on lifespan depends on both gender and dietary nutrient composition in Drosophila melanogaster. Age (Dordr) 2013, 35:69-81.

3. Kang HL, Benzer S, Min KT: Life extension in Drosophila by feeding a drug. Proc Natl Acad Sci USA 2002, 99:838-843.

4. Nikitin $A G$, Navitskas $S$, Gordon LA: Effect of varying doses of caffeine on life span of Drosophila melanogaster. J Gerontol A Biol Sci Med Sci 2008, 63:149-150

5. Lee KS, Lee BS, Semnani S, Avanesian A, Um C-Y, Jeon HJ, Seong KM, Yu K, Min KJ, Jafari M: Curcumin extends life span, improves health span, and modulates the expression of age-associated aging genes in Drosophila melanogaster. Rejuvenation Res 2010, 13:561-570.

6. Spindler SR, Li R, Dhahbi JM, Yamakawa A, Mote P, Bodmer R, Ocorr K, Williams RT, Wang Y, Ablao KP: Statin treatment increases lifespan and improves cardiac health in Drosophila by decreasing specific protein prenylation. PLoS One 2012, 7:e39581.

7. Jafari M, Felgner JS, Bussel II, Hutchili T, Khodayari B, Rose MR, Vince-Cruz C, Mueller LD: Rhodiola: a promising anti-aging Chinese herb. Rejuvenation Res 2007, 10:587-602.

8. Schriner SE, Abrahamyan A, Avanessian A, Bussel I, Maler S, Gazarian M, Holmbeck MA, Jafari M: Decreased mitochondrial superoxide levels and enhanced protection against paraquat in Drosophila melanogaster supplemented with Rhodiola rosea. Free Radic Res 2009, 43:836-843.

9. Schriner SE, Katoozi NS, Pham KQ, Gazarian M, Zarban A, Jafari M: Extension of Drosophila lifespan by Rosa damascena associated with an increased sensitivity to heat. Biogerontology 2012, 13:105-117.

10. Peng C, Zuo Y, Kwan KM, Liang Y, Ma KY, Chan HYE, Huang Y, Yu H, Chen ZY: Blueberry extract prolongs lifespan of Drosophila melanogaster. Exp Gerontol 2012, 47:170-178.

11. Tatar M: The plate half-full: status of research on the mechanisms of dietary restriction in Drosophila melanogaster. Exp Gerontol 2011, 46:363-368

12. Bjedov I, Partridge L: A longer and healthier life with TOR downregulation: genetics and drugs. Biochem Soc Trans 2011, 39:460-465.

13. Partridge L, Alic N, Bjedov I, Piper MDW: Ageing in Drosophila: the role of the insulin/IGF and TOR signaling network. Exp Gerontol 2011, 46:376-381.

14. Mattila J, Bremer A, Ahonen L, Kostiainen R, Puig O: Drosophila FoxO regulates organism size and stress resistance through an adenylate cyclase. Mol Cell Biol 2009, 29:5357-5365.

15. Saratikov AS, Krasnov EA: Rhodiola rosea is a Valuable Medicinal Plant (Golden Root). Tomsk: Tomsk State University Press; 1987.

16. Kelly GS: Rhodiola rosea: a possible plant adaptogen. Altern Med Rev 2001, 6:293-302.
17. Boon-Niermeijer EK, van den Berg A, Wikman G, Wiegant FA: Phytoadaptogens protect against environmental stress-induced death of embryos from the freshwater snail Lymnaea stagnalis. Phytomedicine 2000, 7:389-399.

18. Mattioli L, Perfumi M: Rhodiola rosea $L$. extract reduces stress- and CRFinduced anorexia in rats. J Psychopharmacol (Oxford) 2007, 21:742-750.

19. Wiegant FAC, Surinova S, Ytsma E, Langelaar-Makkinje M, Wikman G, Post JA: Plant adaptogens increase lifespan and stress resistance in $C$. elegans. Biogerontology 2009, 10:27-42.

20. Miller RA: Cell stress and aging: new emphasis on multiplex resistance mechanisms. J Gerontol A Biol Sci Med Sci 2009, 64:179-182.

21. Vaiserman AM: Life extension by anti-aging drugs: hormetic explanation? Am J Pharmacol Toxicol 2008, 3:14-18.

22. Lamming DW, Wood JG, Sinclair DA: Small molecules that regulate lifespan: evidence for xenohormesis. Mol Microbiol 2004, 53:1003-1009.

23. Couzin-Frankel J: Genetics. Aging genes: the sirtuin story unravels. Science 2011, 334:1194-1198.

24. Avanesian A, Khodayari B, Felgner JS, Jafari M: Lamotrigine extends lifespan but compromises health span in Drosophila melanogaster. Biogerontology 2010, 11:45-52.

25. Simpson SJ, Raubenheimer D: Caloric restriction and aging revisited: the need for a geometric analysis of the nutritional bases of aging. $J$ Gerontol A Biol Sci 2007, 62:707-713.

26. Mair W, Piper MDW, Partridge L: Calories do not explain extension of life span by dietary restriction in Drosophila. PLoS Biol 2005, 3:e223.

27. Piper MDW, Partridge L: Dietary restriction in Drosophila: delayed aging or experimental artefact? PLOS Genet 2007, 3:e57.

28. Skorupa DA, Dervisefendic A, Zwiener J, Pletcher SD: Dietary composition specifies consumption, obesity, and lifespan in Drosophila melanogaster. Aging Cell 2008, 7:478-490.

29. Simpson SJ, Raubenheimer D: Macronutrient balance and lifespan. Aging (Albany NY) 2009, 1:875-880.

30. Lee KP, Simpson SJ, Clissold FJ, Brooks R, Ballard JWO, Taylor PW, Soran N, Raubenheimer D: Lifespan and reproduction in Drosophila: new insights from nutritional geometry. Proc Natl Acad Sci USA 2008, 105:2498-2503.

31. Wong R, Piper MDW, Wertheim B, Partridge L: Quantification of food intake in Drosophila. PLoS One 2009, 4:e6063.

32. Wu Q, Zhang Y, Xu J, Shen P: Regulation of hunger-driven behaviors by neural ribosomal S6 kinase in Drosophila. Proc Natl Acad Sci USA 2005, 102:13289-13294.

33. Dann SG, Selvaraj A, Thomas G: mTOR Complex1-S6K1 signaling: at the crossroads of obesity, diabetes and cancer. Trends Mol Med 2007, 13:252-259.

34. Meunier N, Belgacem $\mathrm{YH}$, Martin JR: Regulation of feeding behaviour and locomotor activity by takeout in Drosophila. J Exp Biol 2007, 210:1424-1434.

35. Nässel DR: Insulin-producing cells and their regulation in physiology and behavior of Drosophila. Can J Zool 2012, 90:476-488.

36. Ruaud AF, Thummel CS: Serotonin and insulin signaling team up to control growth in Drosophila. Genes Dev 2008, 22:1851-1855.

37. Falibene A, Rössler W, Josens R: Serotonin depresses feeding behaviour in ants. J Insect Physiol 2012, 58:7-17.

38. Luo J, Becnel J, Nichols CD, Nässel DR: Insulin-producing cells in the brain of adult Drosophila are regulated by the serotonin $5-\mathrm{HT}_{1 \mathrm{~A}}$ receptor. Cell Mol Life Sci 2012, 69:471-484.

39. Sloley BD, Urichuk LJ, Morley P, Durkin J, Shan JJ, Pang PK, Coutts RT: Identification of kaempferol as a monoamine oxidase inhibitor and potential neuroprotectant in extracts of Ginkgo biloba leaves. J Pharm Pharmacol 2000, 52:451-459.

40. van Diermen D, Marston A, Bravo J, Reist M, Carrupt PA, Hostettmann K: Monoamine oxidase inhibition by Rhodiola rosea L. roots. J Ethnopharmacol 2009, 122:397-401.

41. Bonilla E, Medina-Leendertz S, Díaz S: Extension of life span and stress resistance of Drosophila melanogaster by long-term supplementation with melatonin. Exp Gerontol 2002, 37:629-638.

42. Kitani K, Minami C, Isobe K, Maehara K, Kanai S, Ivy GO, Carrillo MC: Why (-) deprenyl prolongs survivals of experimental animals: increase of antioxidant enzymes in brain and other body tissues as well as mobilization of various humoral factors may lead to systemic anti-aging effects. Mech Ageing Dev 2002, 123:1087-1100.

43. Lin Y-J, Seroude L, Benzer S: Extended life-span and stress resistance in the Drosophila mutant methuselah. Science 1998, 282:943-946. 
44. Yamamoto R, Tatar M: Insulin receptor substrate chico acts with the transcription factor FOXO to extend Drosophila lifespan. Aging Cell 2011, 10:729-732

45. Ricklefs RE, Scheuerlein A: Biological implications of the Weibull and Gompertz models of aging. J Gerontol A Biol Sci Med Sci 2002, 57:69-76.

46. Sepulveda S, Shojaeian $\mathrm{P}$, Rauser $\mathrm{CL}$, Jafari M, Mueller LD, Rose MR: Interactions between injury, stress resistance, reproduction, and aging in Drosophila melanogaster. Exp Gerontol 2008, 43:136-145.

47. Minois N, Khazaeli AA, Curtsinger JW: Locomotor activity as a function of age and life span in Drosophila melanogaster overexpressing hsp70. Exp Gerontol 2001, 36:1137-1153.

48. Lithgow GJ, Walker GA: Stress resistance as a determinate of $C$. elegans lifespan. Mech Ageing Dev 2002, 123:765-771.

49. Kurapati R, Passananti HB, Rose MR, Tower J: Increased hsp22 RNA levels in Drosophila lines genetically selected for increased longevity. J Gerontol A Biol Sci Med Sci 2000, 55:552-559.

50. Morrow G, Battistini S, Zhang P, Tanguay RM: Decreased lifespan in the absence of expression of the mitochondrial small heat shock protein Hsp22 in Drosophila. J Biol Chem 2004, 279:43382-43385.

51. O'Brien T, Lis JT: Rapid changes in Drosophila transcription after an instantaneous heat shock. Mol Cell Biol 1993, 13:3456-3463.

52. Castro FA, Mariani D, Panek AD, Eleutherio EC, Pereira MD: Cytotoxicity mechanism of two naphthoquinones (menadione and plumbagin) in Saccharomyces cerevisiae. PLoS One 2008, 3:e3999.

53. Liu Z, Li X, Simoneau AR, Jafari M, Zi X: Rhodiola rosea extracts and salidroside decrease the growth bladder cancer cell lines via inhibition of the mTOR pathway and induction of autophagy. Mol Carcinog 2012, 51:257-267.

54. Eijkelenboom A, Burgering BM: FOXOs: signalling integrators for homeostasis maintenance. Nat Rev Mol Cell Biol 2013, 14:83-97.

55. Schriner SE, Avanesian A, Liu Y, Luesch H, Jafari M: Protection of human cultured cells against oxidative stress by Rhodiola rosea without activation of antioxidant defenses. Free Radic Biol Med 2009, 47:577-584.

56. Jafari M: Drosophila melanogaster as a model system for the evaluation of anti-aging compounds. Fly (Austin) 2010, 4:253-257.

57. Middleton CA, Nongthomba U, Parry K, Sweeney ST, Sparrow JC, Elliott CJH: Neuromuscular organization and aminergic modulation of contractions in the Drosophila ovary. BMC Biol 2006, 4:17.

58. Lee G, Villella A, Taylor BJ, Hall JC: New reproductive anomalies in fruitlessmutant Drosophila males: extreme lengthening of mating durations and infertility correlated with defective serotonergic innervation of reproductive organs. J Neurobiol 2001, 47:121-149.

59. Promislow DEL, Tatar M, Khazaeli AA, Curtsinger JW: Age-specific patterns of genetic variance in Drosophila melanogaster. I. Mortality. Genetics 1996, 143:839-848.

60. Lushchak OV, Gospodaryov DV, Rovenko BM, Glovyak AD, Yurkevych IS, Klyuba VP, Shcherbij MV, Lushchak VI: Balance between macronutrients affects life span and functional senescence in fruit fly Drosophila melanogaster. J Gerontol A Biol Sci Med Sci 2012, 67:118-125.

61. Mueller LD, Nusbaum TJ, Rose MR: The Gompertz equation as a predictive tool in demography. Exp Gerontol 1995, 30:553-569.

62. Lushchak OV, Rovenko BM, Gospodaryov DV, Lushchak VI: Drosophila melanogaster larvae fed by glucose and fructose demonstrate difference in oxidative stress markers and antioxidant enzymes of adult flies. Comp Biochem Physiol A Mol Integr Physiol 2011, 160:27-34

63. Chadha A: The effect of light wavelength on mating, copulation \& fitness in Drosophila melanogaster. Enquiries J Interdiscip Stud High School Stud 2008, 3:1-8.

doi:10.1186/2046-2395-2-5

Cite this article as: Gospodaryov et al: Lifespan extension and delay of age-related functional decline caused by Rhodiola rosea depends on dietary macronutrient balance. Longevity \& Healthspan 2013 2:5.

\section{Submit your next manuscript to BioMed Central and take full advantage of:}

- Convenient online submission

- Thorough peer review

- No space constraints or color figure charges

- Immediate publication on acceptance

- Inclusion in PubMed, CAS, Scopus and Google Scholar

- Research which is freely available for redistribution 